\title{
Using Capacitance Sensors for the Continuous Measurement of the Water Content in the Litter Layer of Forest Soil
}

\author{
Mioko Ataka, ${ }^{1}$ Yuji Kominami, ${ }^{2}$ Takafumi Miyama, ${ }^{2}$ Kenichi Yoshimura, \\ Mayuko Jomura, ${ }^{3}$ and Makoto Tani ${ }^{1}$ \\ ${ }^{1}$ Laboratory of Forest Hydrology, Division of Environmental Science and Technology, Graduate School of Agriculture, \\ Kyoto University, Kyoto 606-8502, Japan \\ ${ }^{2}$ Kansai Research Center, Forestry and Forest Products Research Institute, Kyoto 612-0855, Japan \\ ${ }^{3}$ College of Bioresource Sciences, Nihon University, Fujisawa, Kanagawa 252-0880, Japan \\ Correspondence should be addressed to Mioko Ataka; teshimamioko@yahoo.co.jp
}

Received 7 January 2014; Revised 3 March 2014; Accepted 10 March 2014; Published 3 April 2014

Academic Editor: Davey Jones

Copyright (c) 2014 Mioko Ataka et al. This is an open access article distributed under the Creative Commons Attribution License, which permits unrestricted use, distribution, and reproduction in any medium, provided the original work is properly cited.

\begin{abstract}
Little is known about the wetting and drying processes of the litter layer (L layer), likely because of technical difficulties inherent in nondestructive water content (WC) monitoring. We developed a method for continuously measuring the WC of leaf litter (the "LWC method") in situ using capacitance sensors. To test variants of this approach, five (for the LWC_5) or ten (for the LWC_10 method) Quercus serrata leaves were attached around capacitance sensors. The output voltage used for each LWC method was linearly correlated with the gravimetric WC (LWC 5 : $R^{2}=0.940$; LWC_10: $R^{2}=0.942$ ), producing different slopes for each calibration line. For in situ continuous measurements of WC in the L layer, two sensors were used, one placed on top of the L layer and the other at the boundary between the $\mathrm{L}$ and mineral layers. The average continuous WC of the L layer was then calculated from the output voltage of the two sensors and the calibration function, and this value was linearly correlated with the gravimetric WC $\left(R^{2}=0.697\right)$. However, because the L layer characteristics (e.g., thickness, water-holding capacity, and species composition) may differ among study sites, appropriate approaches for measuring this layer's moisture properties may be needed.
\end{abstract}

\section{Introduction}

The litter layer (L layer) comprises the uppermost soil layer and plays an important role in the water dynamics of the forest floor. For example, this layer limits the amount of water that can infiltrate into and/or evaporate from the soil [1-3]. Despite the importance of the L layer in hydrological processes, water dynamics in this layer are often overlooked in studies of forest hydrology, mainly because of the technical difficulties in making accurate measurements.

The L layer, which contains annually refreshed litter, is also a significant source of carbon in soil for heterotrophic organisms. Owing to the input of labile organic matter, the microbial activity in this layer is typically higher than that of lower soil layers [4] and is mainly regulated by environmental factors (e.g., moisture and temperature) $[5,6]$. In addition, the moisture status of this layer changes more rapidly than that of lower soil layers $[7,8]$ because the L layer is directly exposed to rain, solar radiation, and wind. The wetting and drying cycles in this layer lead to dynamic temporal variations in $\mathrm{CO}_{2}$ efflux [9], which strongly relates to the soil carbon budget. In addition, temporal variations in $\mathrm{CO}_{2}$ efflux from the $\mathrm{L}$ layer are associated with varied environmental factors, which were continuously measured at an interval of several tens of minutes in an improved automated chamber system $[10,11]$. However, to evaluate $\mathrm{CO}_{2}$ efflux as a function of the L layer's wetting and drying processes, continuous measurements of both the WC of this layer and the $\mathrm{CO}_{2}$ flux are required.

Some researchers have attempted to continuously measure water content (WC) of the L layer in situ $[9,12,13]$. Hanson et al. [13] used an approach based on the use of electricalimpedance grids for recording leaf wetness reported by Gillespie and Kidd [14]. This approach was used to monitor 
the resistance or voltage between two clips attached to Quercus prinus leaves $3 \mathrm{~cm}$ apart along the midvein. The method was also modified with the use of wood pieces instead of intact leaves to avoid changes in the waterholding capacity of the material through decomposition over time [9]. Börner et al. [12] tested a different approach that employed two-time-domain reflectometry (TDR) probes placed directly into the mineral soil and at the boundary of the L layer and the surface of the mineral soil. These approaches used specialized techniques and calibration function specialized for the L layer condition of their measurement sites because the L layer condition (e.g., thickness, water-holding capacity, and species composition) is more variable than that of mineral soil layer. Therefore, appropriate approaches for measuring the L layer's moisture condition for individual forest types may be required.

Recently, a small and thin capacitance sensor was developed which allows measurement of WC in restricted areas. In this study, we developed a method that uses such capacitance sensors to measure the WC of leaf litter, which we termed the "LWC method." To measure WC of leaf litter with capacitance sensors, some intact leaf litter was closely attached around the sensor with rubber bands. In the laboratory, the output voltage of the LWC method was calibrated against the gravimetric $\mathrm{WC}\left(\mathrm{WC}_{\text {weight }}\right)$ of the leaf litter attached to the sensor. Using this LWC method, we continuously measured the WC of the L layer in situ ( $\mathrm{WC}_{\mathrm{LWC} \text { method }}$ ) and compared the observed data with $\mathrm{WC}_{\text {weight }}$ obtained by destructive sampling of the L layer.

\section{Site Description}

We tested our approach for continuously measuring the L layer's WC in situ in the Yamashiro Experimental Forest (YMS) in the southern region of the Kyoto Prefecture, Japan $\left(34^{\circ} 47^{\prime} \mathrm{N}, 135^{\circ} 50^{\prime} \mathrm{E}\right)$. The study site was a 1.7 ha watershed with an annual mean air temperature of $15.5^{\circ} \mathrm{C}$ (summer hourly maximum: $34.8^{\circ} \mathrm{C}$; winter hourly minimum: $-3.9^{\circ} \mathrm{C}$ ) and an annual mean precipitation of $1449 \mathrm{~mm}$. The rainy season generally occurs from early June to mid-July. Daily rates of evaporation from the forest floor are $0.4-0.8 \mathrm{~mm} \mathrm{day}^{-1}$ for 1-2 days after precipitation, declining to $0.2-0.3 \mathrm{~mm}^{\text {day }}{ }^{-1}$ thereafter [15]. Here, the L layer's WC dynamically changes from wet to dry within a few days. The large changes of the L layer's WC strongly influence on the evaporation rate from the forest floor the L layer.

In this ecosystem, the soils are regosols of sandy loam or loamy sand and contain fine gravel (53\% by mass) composed of residual quartz crystals from parent granite material [16]. The soil layer is generally thin and immature. In addition, deciduous broadleaved, evergreen broadleaved, and coniferous tree species account for $66 \%, 28 \%$, and $6 \%$ of the living tree biomass, respectively [17]. The forest and the associated leaf litter are dominated by Quercus serrata Thunb, which accounted for $33 \%$ of the biomass at the time of the study. Thus, the L layer is mostly composed of Quercus serrata litter at a thickness of approximately 3-4 cm.

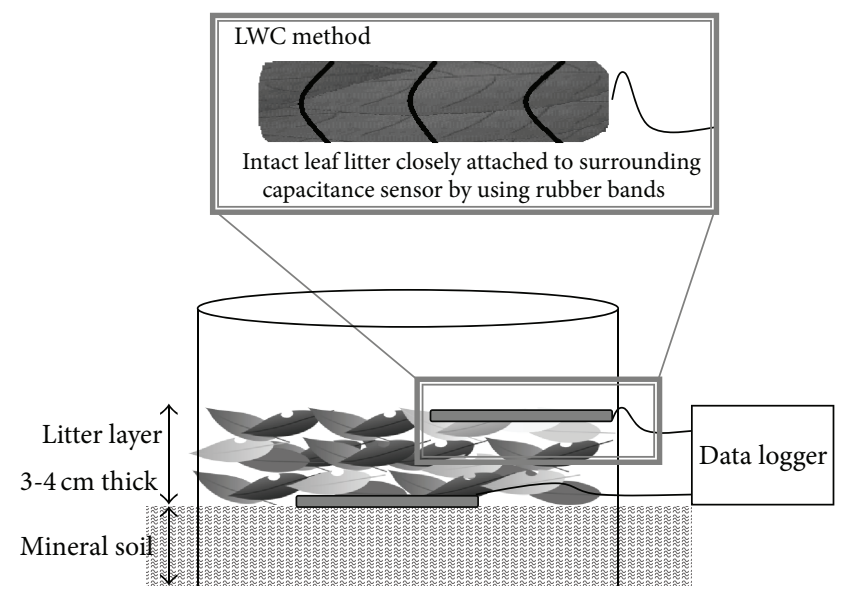

FIGURE 1: Design and installation of sensors used in the LWC method.

\section{Materials and Methods}

3.1. The LWC Method. In this study, we used plate-type sensors ( $\mathrm{ECH}_{2} \mathrm{O}$ EC-5, Decagon Devices Inc., Pullman, WA), which are suitable for closely attaching leaves around the sensors, for the continuous measurement of the L layer's WC. Each EC-5 sensor was operated at $70 \mathrm{MHz}$ and consisted of a short two-prong $(5.6 \mathrm{~cm}$ long) sensor, circuitry, and data cable. During the study, the supply voltage to the sensor was fixed at $3.5 \mathrm{~V}$ [18], and the corresponding output voltage was recorded with the data logger (Datamark LS-3000 PtV; Hakusan, Japan).

Leaf litter that had fallen in the previous year was collected from the forest floor in January 2013. The leaves were attached as homogeneously as possible on both sides of the sensors with rubber bands, and the leaf edges that extended beyond the sensors were tightly wrapped around the probes to prevent the creation of interstices between the sensor plate and leaves (Figure 1). As a result, the sensor plate was completely covered with leaves. Using this method, capacitance sensor could stably capture the WC of the attached leaves, which would be in equilibrium with WC of the surrounding L layer.

To consider the effect of the amount of leaves that were attached to sensor on output voltage of the EC-5 sensor, we tested two variants of the LWC method, where five (the LWC_5 method) or ten (the LWC_10 method) Quercus serrata leaves were attached to the sensors.

3.2. Calibration. We assessed the relationship between the output voltage generated from the LWC method and the $\mathrm{WC}_{\text {weight }}$. To consider the effect of the amount of leaves attached to sensor on the output voltage from the EC-5 sensor, we measured the output voltage generated by the LWC_5 and LWC_10 methods and compared those voltages to the $\mathrm{WC}_{\text {weight }}$ of the leaves attached to the sensor at various moisture conditions ( $n=77$ or 66 ). To create samples that ranged from near zero to the maximum WC, leaf samples were soaked in water for 48 hours and then allowed to 
naturally dry to different WC levels. Water droplets on leaf samples were shaken off before attaching sensors. After each measurement, the leaves were removed from the sensor and oven-dried at $65^{\circ} \mathrm{C}$ for $48 \mathrm{~h}$. WC was calculated according to the following equation:

$$
\mathrm{WC}_{\text {weight }}=\frac{(\mathrm{FW}-\mathrm{DW})}{\mathrm{DW}},
$$

where FW and DW are the fresh and dry weights of the leaf litter sample (g), respectively.

\section{In Situ Measurement of WC in the L Layer}

The $\mathrm{WC}$ of the $\mathrm{L}$ layer was measured as $\mathrm{WC}_{\text {weight }}$ and $\mathrm{WC}_{\mathrm{LWC} \text { method }}$ in the field. $\mathrm{WC}_{\text {weight }}$ was measured on 12 sampling days from May to September 2013. Twelve PVC collars (area: $323 \mathrm{~cm}^{2}$ ) were placed in a $2 \times 4 \mathrm{~m}$ area on January 2013, and $15 \mathrm{~g}$ (dry weight) of newly fallen leaf litter was placed in each collar. This weight corresponded to the approximate litter-fall mass at this site [17]. The thickness of the L layer was approximately $3-4 \mathrm{~cm}$. On each sampling day, we selected four or five leaves to use in calculations of $\mathrm{WC}_{\text {weight }}$ in the L layer of each collar and enclosed those samples in plastic bags. The fresh weight of the sample was measured in the laboratory within $24 \mathrm{~h}$ after sampling, and samples were oven-dried at $65^{\circ} \mathrm{C}$ for $48 \mathrm{~h}$. The samples were returned to the collars within one week after collection.

In addition, the $\mathrm{WC}_{\mathrm{LWC} \text { method }}$ of the $\mathrm{L}$ layer was continuously measured in $30 \mathrm{~min}$ intervals from May to September 2013. To compare $\mathrm{WC}_{\mathrm{LWC} \text { method }}$ and $\mathrm{WC}_{\text {weight, }}$, one $\mathrm{PVC}$ collar equipped with a sensor for the measurement of the $\mathrm{WC}_{\mathrm{LWC} \text { method }}$ was placed adjacent to the sampling area, and $15 \mathrm{~g}$ of newly fallen leaf litter was supplied to the collar. Measurements of $\mathrm{WC}_{\mathrm{LWC} \text { method }}$ were made according to the LWC_5 method because the ratio of the leaf area to the unit ground surface area in each collar was approximately 4-5. In this study, $\mathrm{WC}_{\mathrm{LWC} \text { method }}$ measurements were conducted at two levels, on top of the L layer and at the boundary between the L layer and the mineral soils (Figure 1), to completely capture the large vertical variation in the WC inside the $\mathrm{L}$ layer [19]. We estimated the WC of the L layer using the average $\mathrm{WC}_{\mathrm{LWC} \text { method }}$ calculated from the output voltage of the two sensors and the calibration line of the LWC_5 method.

\section{Results and Discussion}

5.1. The LWC Method. The output voltage generated by the LWC method was calibrated by and linearly correlated with the $\mathrm{WC}_{\text {weight }}$ of the leaves attached to the sensors (Figure 2; LWC_5: $R^{2}=0.940$; LWC_10: $R^{2}=0.942$ ). The output voltages resulting from the LWC_5 method ranged from 0.265 to $0.444 \mathrm{~V}$ for a range of $\mathrm{WC}_{\text {weight }}$ from 0.026 to $2.637 \mathrm{~g} \mathrm{~g}^{-1}$, respectively. The output voltages resulting from the LWC_10 method ranged from 0.267 to $0.491 \mathrm{~V}$ for $\mathrm{WC}_{\text {weight }}$ ranging from 0.000134 to $1.810 \mathrm{~g} \mathrm{~g}^{-1}$, respectively. However, different calibration functions were obtained for the LWC 5 and LWC_10 methods. This difference could be explained by differences in the thickness of the layer of leaves attached to

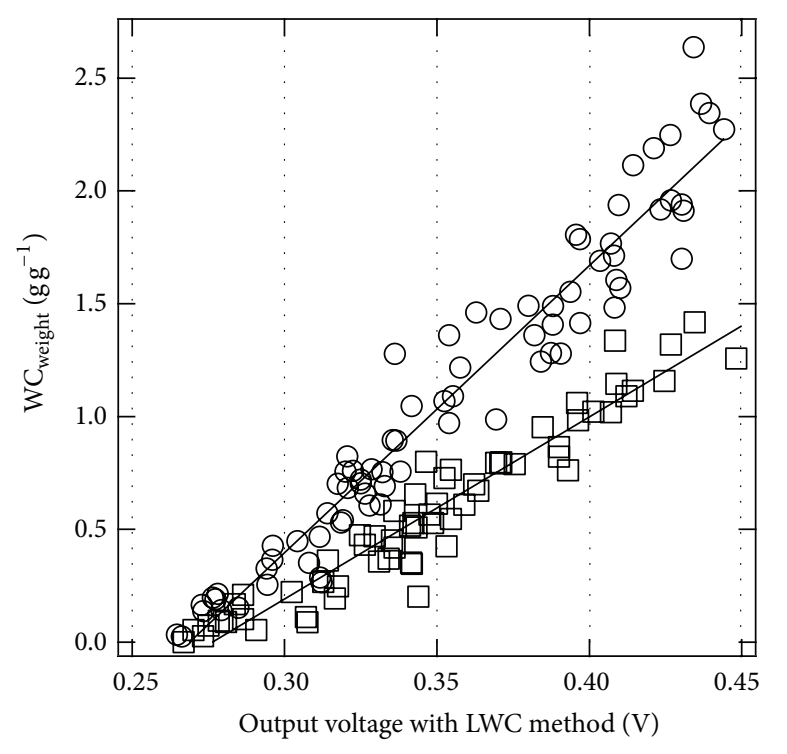

LWC_5

$\square$ LWC_10

FIGURE 2: The relationship between the LWC method's output voltage and the gravimetric water content $\left(\mathrm{WC}_{\text {weight }}\right)$ of the leaves attached to the sensors. Circles show the data collected with the LWC_5 method ( $\left.n=77, y=12.725 x-3.4211, R^{2}=0.940\right)$, where five Quercus serrata leaves were attached to the sensor with rubber bands. Squares show the data collected with the LWC_10 method ( $\left.n=66, y=8.0696 x-2.2298, R^{2}=0.942\right)$, which used ten Quercus serrata leaves.

the sensor plates. Imoto et al. [20] reported that EC-5 sensors could detect moisture to a maximum distance of $2-3 \mathrm{~cm}$ from the sensor plate. In this study, the total thicknesses of the sensor plates and attached leaves were 0.5 and $1 \mathrm{~cm}$ for the LWC_5 and LWC_10 methods, respectively.

Both the LWC_5 and LWC_10 methods allowed for the measurement of $\mathrm{WC}_{\text {weight }}$ of the leaves attached to the sensors (Figure 2), and the amount of leaf litter attached to the sensor could affect the output voltage of the sensor. Thus, we need to obtain individual calibration function between output voltage of the $\mathrm{LWC}$ method and $\mathrm{WC}_{\text {weight }}$ of the leaves attached to the sensors, depending on the amount of leaves attached to the sensor.

5.2. Continuous Measurement of WC in the L Layer with the LWC Method. $\mathrm{WC}_{\mathrm{LWC} \text { method }}$ was continuously measured in the field and compared to $\mathrm{WC}_{\text {weight }}$ of litter samples collected over 12 sampling days (Figures 3 and 4 ). $\mathrm{WC}_{\mathrm{LWC} \text { method was }}$ corrected to $\mathrm{WC}_{\text {weight }}\left(R^{2}=0.697\right)$. However, $\mathrm{WC}_{\text {LWC method }}$ was larger than $W^{-} C_{\text {weight }}$ (Figure 3) when WC was very low. In this case, temporal variation in $\mathrm{WC}_{\mathrm{LWC} \text { method }}$ was very low (Figure 4). This result suggests that the sensors placed at the boundary between the L layer and the mineral soil layers captured the moisture properties of the mineral soil, which remained wet even as the L layer dried.

On the other hand, estimates of $\mathrm{WC}_{\mathrm{LWC} \text { method }}$ tended to be lower than $\mathrm{WC}_{\text {weight }}$ with larger standard deviations at 


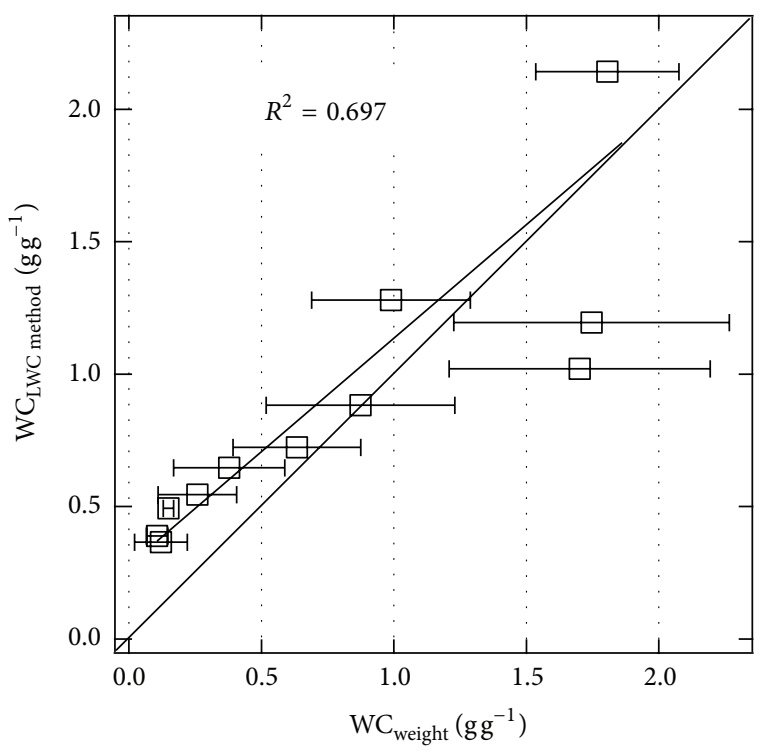

FIGURE 3: The relationship between the water content of leaf litter samples obtained using the LWC method $\left(\mathrm{WC}_{\mathrm{LWC}} 5\right.$ method $)$ and the gravimetric water content $\left(\mathrm{WC}_{\text {weight }}\right)\left(R^{2}=0.697\right)$. Error bars represent the standard deviation.

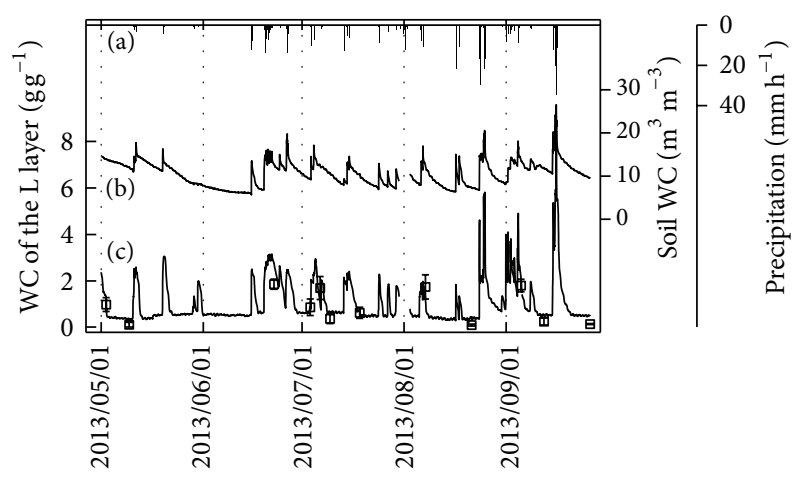

FIGURE 4: Temporal variation in (a) hourly precipitation, (b) volumetric soil water content at a depth of $0-5 \mathrm{~cm}$ in mineral soil depth, and (c) water content obtained using the LWC method $\left(\mathrm{WC}_{\mathrm{LWC}-5 \text { method }}\right)$ and the gravimetric water content $\left(\mathrm{WC}_{\text {weight }}\right.$; Square) in the L layer in a temperate broad-leaved secondary forest at Yamashiro Experimental Forest (YMS) from May to September 2013. Error bars are standard deviations.

higher WC levels (Figure 3), especially on 6 July and 7 August, 2013 (Figure 4). These results suggest that the spatial variation in the WC of the L layer was large among the experimental collars, even though the 12 collars were closely organized across a limited area $(2 \times 4 \mathrm{~m})$. We suspect that the wetting and drying processes in the L layer differed across even this limited area. In fact, there was a large spatial variation in solar radiation and rainfall on the forest floor after penetrating the canopy, which are factors associated with the wetting and drying of the L layer. Therefore, in future studies, it will be important for investigators to first determine the appropriate areas for sensor placement. For example, to evaluate $\mathrm{CO}_{2}$ efflux from the L layer during the drying and wetting cycles, the sensor should be placed near the object of $\mathrm{CO}_{2}$ flux measurement.

As seen in Figure 4(c), there were large fluctuations in $\mathrm{WC}_{\mathrm{LWC} \text { method }}$ of the L layer, ranging from 0.235 to $8.434 \mathrm{~g} \mathrm{~g}^{-1}$. Such frequent fluctuations resulted from the drying and wetting cycles of this L layer. The WC of the L layer increased immediately after rainfall (within a few hours) and then decreased within a few days after rainfall, ultimately reaching a steady state. Tamai and Hattori [15] also reported that daily evaporation from the L layer was larger, 1-2 days after rainfall than afterward. Furthermore, the wetting and drying cycles of the $\mathrm{L}$ layer differed from those of the soil $[9,13]$. The soil WC decreased steadily until the next rainfall even over the extended dry period from 1 to 15 June (Figure 4(b)). Moreover, $\mathrm{WC}_{\mathrm{LWC} \text { method }}$ increased following a small rainfall event between 28 and 30 May (Figure 4(c)), but that increase was not detected by the WC sensor in the soil. Thus, only the L layer became wet as a result of rain, dew, and fog formation, which can input significant amounts of water into the ecosystem [21]. The continuous measurement of the WC of the L layer therefore allowed for a better understanding of water movement and soil $\mathrm{CO}_{2}$ efflux on the forest floor.

\section{Conclusion}

We developed the LWC method for the continuous in situ monitoring of the $\mathrm{WC}$ of the L layer. Output voltages resulting from both the LWC_5 and LWC_10 methods were strongly correlated with $\mathrm{WC}_{\text {weight }}$, demonstrating that both methods could be used for the intended purpose. The LWC_5 method also captured the temporal variation in WC in our study site reasonably well. However, we suspect that the amount of leaf litter required for attachment to the sensors and the installation of the sensors should be specific to the L layer's properties which can differ between sites. Thus, future studies should examine site-specific aspects of the experimental design for the LWC method.

Tamai and Hattori [15] described a model for estimating WC in the L layer every $30 \mathrm{~min}$ as a function of solar radiation and rainfall. This model would be a suitable tool for estimating temporal variation in the L layer's WC at the forest stand level. However, spatial variation in the WC of the L layer can be large on a forest floor. The LWC method allows for the measurement of the L layer's WC in a small area. A comparison between estimates of WC as calculated from this model and from the LWC method is needed to better understand the role of the L layer in hydrological processes.

One disadvantage of the use of intact leaf litter as part of the LWC method is that the structure of litter changes with decomposition over time, altering the corresponding form of the calibration equation $[9,13]$. Therefore, the use of synthetic fiber cloth, which has a similar water-holding capacity to leaf litter, may be required for long-term monitoring instead of natural leaf litter. This approach would also be applicable to the measurement of the WC of sticks and other hard objects. In general, the LWC method can provide estimates of the WC of the L layer, and the continuous in situ measurement of WC 
could contribute to models of $\mathrm{CO}_{2}$ efflux from the $\mathrm{L}$ layer following rainfall.

\section{Conflict of Interests}

The authors declare that there is no conflict of interests regarding the publication of this paper.

\section{Acknowledgments}

This study was partly supported by a Grant-in-Aid for Scientific Research (B) (20380182). The authors also thank Dr. Yoshiko Kosugi and the members of the Forest Hydrology Laboratory at Kyoto University for the helpful advice and aid in field and laboratory measurements.

\section{References}

[1] H. T. Park, S. Hattori, and T. Tanaka, "Development of a numerical model for evaluating the effect of litter layer on evaporation," Journal of Forest Research, vol. 3, pp. 25-33, 1998.

[2] K. B. Wilson, P. J. Hanson, and D. D. Baldocchi, "Factors controlling evaporation and energy partitioning beneath a deciduous forest over an annual cycle," Agricultural and Forest Meteorology, vol. 102, no. 2-3, pp. 83-103, 2000.

[3] J. Ogée and Y. Brunet, "A forest floor model for heat and moisture including a litter layer," Journal of Hydrology, vol. 255, no. 1-4, pp. 212-233, 2002.

[4] J. Šnajdr, V. Valášková, V. Merhautová, J. Herinková, T. Cajthaml, and P. Baldrian, "Spatial variability of enzyme activities and microbial biomass in the upper layers of Quercus petraea forest soil," Soil Biology and Biochemistry, vol. 40, no. 9, pp. 2068-2075, 2008.

[5] A. M. O'Connell, "Microbial decomposition (respiration) of litter in eucalypt forests of South-Western Australia: an empirical model based on laboratory incubations," Soil Biology and Biochemistry, vol. 22, no. 2, pp. 153-160, 1990.

[6] J. P. Schimel, J. M. Gulledge, J. S. Clein-Curley, J. E. Lindstrom, and J. F. Braddock, "Moisture effects on microbial activity and community structure in decomposing birch litter in the Alaskan taiga," Soil Biology and Biochemistry, vol. 31, no. 6, pp. 831-838, 1999.

[7] X. Lee, H.-J. Wu, J. Sigler, C. Oishi, and T. Siccama, "Rapid and transient response of soil respiration to rain," Global Change Biology, vol. 10, no. 6, pp. 1017-1026, 2004.

[8] K. Savage, E. A. Davidson, A. D. Richardson, and D. Y. Hollinger, "Three scales of temporal resolution from automated soil respiration measurements," Agricultural and Forest Meteorology, vol. 149, no. 11, pp. 2012-2021, 2009.

[9] W. Borken and E. Matzner, "Reappraisal of drying and wetting effects on C and N mineralization and fluxes in soils," Global Change Biology, vol. 15, no. 4, pp. 808-824, 2009.

[10] E. Berryman, J. D. Marshall, T. Rahn, M. Litvak, and J. Butnor, "Decreased carbon limitation of litter respiration in a mortalityaffected pinon-juniper woodland," Biogeosciences, vol. 10, pp. 1625-1634, 2013.

[11] M. Jomura, Y. Kominami, and M. Ataka, "Differences between coarse woody debris and leaf litter in the response of heterotrophic respiration to rainfall events," Journal of Forest Research, vol. 17, pp. 305-311, 2012.
[12] T. Börner, M. G. Johnson, P. T. Rygiewicz, D. T. Tingey, and G. D. Jarrell, "A two-probe method for measuring water content of thin forest floor litter layers using time domain reflectometry," Soil Technology, vol. 9, no. 3, pp. 199-207, 1996.

[13] P. J. Hanson, E. G. O’Neill, M. L. S. Chambers, J. S. Riggs, J. D. Joslin, and M. H. Wolfe, "Soil respiration and litter decomposition," in North America Temperate Deciduous Forest Responses to Changing Precipitation Regimes, P. J. Hanson and S. D. Wullschleger, Eds., pp. 163-189, Springer, New York, NY, USA, 2003.

[14] T. J. Gillespie and G. E. Kidd, "Sensing duration of leaf moisture retention using electrical impedance grids," Canadian Journal of Plant Science, vol. 58, pp. 179-187, 1978.

[15] K. Tamai and S. Hattori, "Modeling of evaporation from forest floor in a deciduous broad-leaved forest and its application to basin," Journal of Forest Research, vol. 76, pp. 233-241, 1994 (Japanese).

[16] S. Kaneko, N. Akieda, F. Naito, K. Tamai, and Y. Hirano, "Nitrogen budget of a rehabilitated forest on a degraded granitic hill," Journal of Forest Research, vol. 12, no. 1, pp. 38-44, 2007.

[17] Y. Goto, Y. Kominami, T. Miyama, K. Tamai, and Y. Kanazawa, "Aboveground biomass and net primary production of a broadleaved secondary forest in the southern part of Kyoto prefecture, central Japan," Bulletin of Forestry and Forest Products Research Institute, vol. 387, pp. 115-147, 2003 (Japanese).

[18] H. R. Bogena, J. A. Huisman, C. Oberdörster, and H. Vereecken, "Evaluation of a low-cost soil water content sensor for wireless network applications," Journal of Hydrology, vol. 344, no. 1-2, pp. 32-42, 2007.

[19] M. Ataka, Y. Kominami, M. Jomura, K. Yoshimura C Uematsu, and C. Uematsu, " $\mathrm{CO}_{2}$ efflux from leaf litter focused on spatial and temporal heterogeneity of moisture," Journal of Forest Research, vol. 19, pp. 295-300, 2014.

[20] H. Imoto, T. Nishimura, and T. Miyazaki, "Calibration and applicability of EC-5 sensor," Journal of the Japanese Society of Soil Physics, vol. 114, pp. 27-31, 2010 (Japanese).

[21] M. S. Carbone, C. J. Still, A. R. Ambrose et al., "Seasonal and episodic moisture controls on plant and microbial contributions to soil respiration," Oecologia, vol. 167, no. 1, pp. 265-278, 2011. 

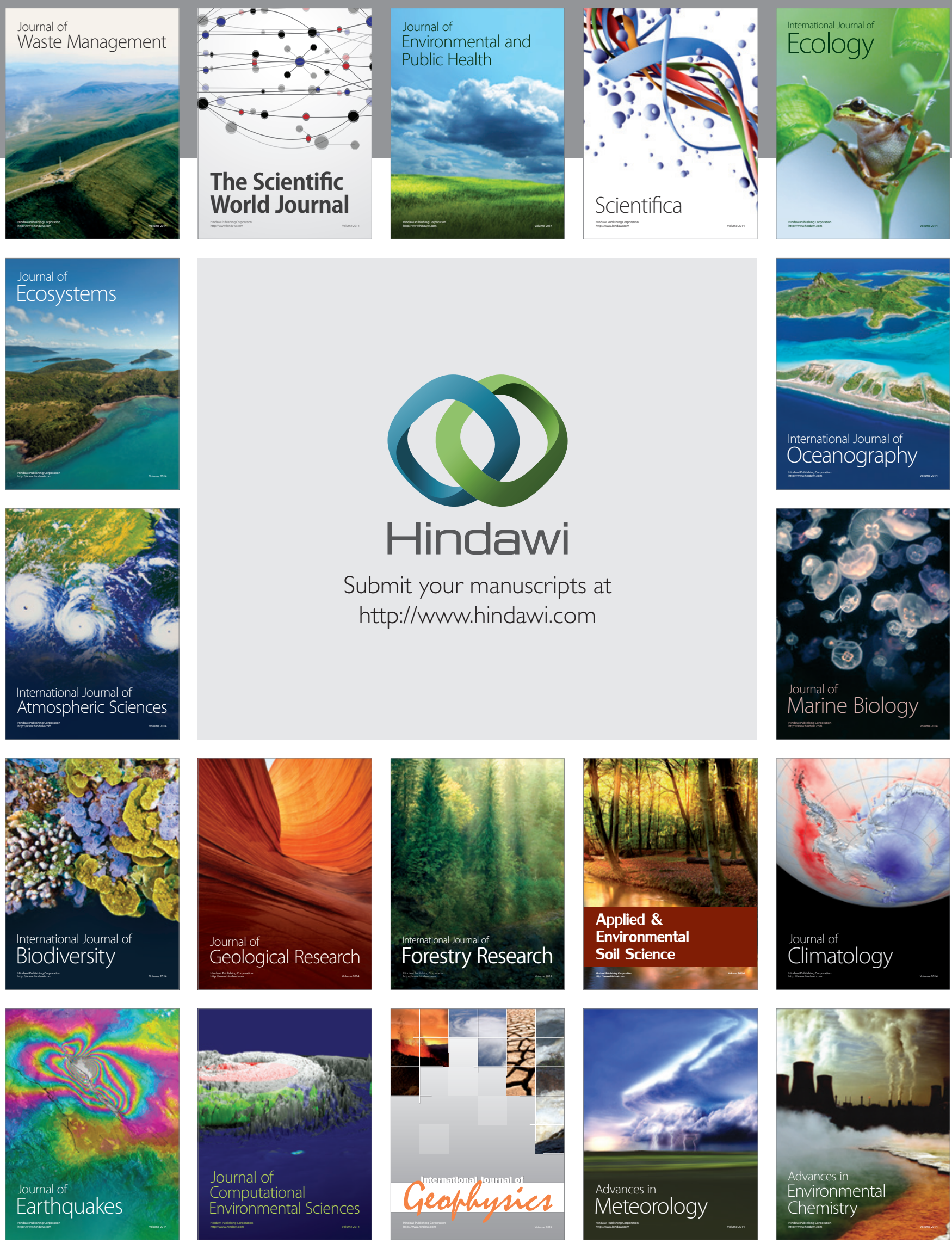